\title{
FREUD E HEIDEGGER: UM PARALELO ENTRE OS CONCEITOS DE ANGÚSTIA E SER-PARA-A-MORTE
}

FREUD AND HEIDEGGER: A PARALLEL BETWEEN ANGUST AND BE-TO-DEATH

CONCEPTS

\author{
Camila Fortes Monte FRANKLIN ${ }^{1}$ \\ Ana Regina Barros RÊGO²
}

Resumo: O presente artigo tem como objetivo traçar um paralelo entre o conceito de angústia desenvolvido por Sigmund Freud (1930) e o conceito de ser-para-a-morte desenvolvido por Martin Heidegger (1927). Esse comparativo busca analisar sobre como o conceito de angústia consegue avançar entre o campo filosófico e psicanalítico refletindo de modo a se dialogarem e se confrontarem. Além disso, refletir sobre aspectos da existência do ser enquanto sujeito transformador que se atualiza nas relações de mundo.

Palavras-chave: angústia. ser-para-a-morte. filosofia. psicanálise.

Abstract: This paper aims to draw a parallel between the concept of anguish developed by Sigmund Freud (1930) and the concept of being-to-die developed by Martin Heidegger (1927). This comparative seeks to analyze how the concept of anguish can advance between the philosophical and psychoanalytic field reflecting in order to dialogue and confront each other. In addition, reflect on aspects of the existence of being as a transforming subject that is updated in world relations.

Keywords: anguish. be-to-death. philosophy. psychoanalysis.

\section{INTRODUÇÃO}

Podemos facilmente encontrar um leque de estudos sobre a angústia psicanalítica em Sigmund Freud, bem como uma variedade de estudos sobre o conceito de ser-para-a-morte desenvolvido pelo filósofo alemão Martin Heidegger. Alguns pontos específicos entre o pensamento desses autores dialogam e entram em conflito, dentre eles, a ideia de angústia, a morte, o mal-estar, um Eu que reflete sobre sua existência em meio à angústia, dentre outros. E em contextos temporais próximos, percebemos como o campo da filosofia e da psicanálise desenvolvem, cada um em seu modo e domínio, uma reflexão do sentido do ser, de existência e conhecimento de si diante os conflitos cotidianos.

Ao desenvolver a psicanálise, Sigmund Freud reconheceu ter elaborado duas diferentes teorias da angústia. Em seu texto "Inibição, sintoma e angústia" (1926) o psicanalista aponta que a

\footnotetext{
${ }^{1}$ Jornalista. Mestranda no Programa de Pós-Graduação em Comunicação da UFPI. Pesquisadora do NUJOC. Bolsista FAPEPI. E-mail: camilafortesmonte@gmail.com.

${ }^{2}$ Jornalista. Doutora em Comunicação. Coordenadora do NUJOC. E-mail: anareginarego@gmail.com
} 
angústia seria o único afeto originário do sujeito e que seria o único que não poderia ser posto em dúvida. Freud também traça um histórico do que denomina de angústia, originária de um mal-estar, da sensação de um desabrigo.

Martin Heidegger em todo seu histórico da filosofia alemã, apresenta reflexões sobre a existência de um ser em essência (presença), e em sua obra "Ser e Tempo" (1927) coloca o homem como sujeito único capaz de questionar essa existência própria. Sua analítica existencial parte do conceito de Dasein, ou seja, "o ente que nós mesmos somos, que em sua essência relaciona-se com o ser, com o mundo; o ente que é fundamentalmente 'ser-no-mundo"'. O autor também desenvolve seu conceito de angústia, como uma disposição de uma ameaça e suas tensões.

A angústia (...) é a disposição que permite que se mantenha aberta a ameaça absoluta e insistente de si mesmo, que emerge do ser mais próprio e singular da pre-sença. $\mathrm{Na}$ angústia, a presença dispõe-se frente ao nada da possível impossibilidade de sua existência. A angústia se angustia pelo poder-ser daquele ente assim determinado, abrindo-lhe a possibilidade mais extrema. Porque o antecipar simplesmente singulariza a presença e, nessa singularização, torna certa a totalidade de seu poder-ser, a disposição fundamental da angústia pertence ao compreender de si mesma, própria da presença (HEIDEGGER, 2015, p. 343).

Assim, o presente artigo busca colocar a visão filosófica de Heidegger ao considerar o serpara-a-morte como resultado de um confronto com a morte em sentido ontológica-existencial para a qual o ser é lançado em meio à angústia, e dialogar com o pensamento de Freud ao considerar a angústia um acontecimento resultante de confrontos com a morte. Para isso, se faz necessário uma breve contextualização com o entendimento de Freud sobre a angústia e a ideia de mal-estar, buscando construir um histórico do sofrimento psíquico e suas transformações ao longo dos anos.

Em seguida, trazemos o conceito de ser-para-a-morte desenvolvido por Heidegger, bem como sua ótica sobre a disposição da angústia do ser, considerado pelo autor como estado fundamental da existência humana. Trazemos também uma reflexão posta, ainda por Heidegger, sobre a vida em sua potência ontológica-existencial, desenvolvida através da cotidianidade dos sujeitos e da totalidade da presença. Por fim, estabelecemos um diálogo entre o conceito de porvir desenvolvido por Heidegger em "Ser e Tempo" e o mesmo conceito desenvolvido por Michel Foucault em " $A$ Hermenêtica do sujeito" (2007\2010), ao apontar uma inerente necessidade humana de preocupação com o porvir.

Dito isto, iniciamos o presente trabalho com uma breve contextualização de angústia desenvolvida por Sigmund Freud.

\section{ANGÚSTIA EM FREUD}


Ao longo dos tempos, a ideia de sofrimento foi transformada, reconhecida e tratada de diferentes maneiras. O mal-estar fez parte do homem primitivo e continua presente no homem contemporâneo, porém, de maneiras distintas, o homem busca formas de afastar, amenizar ou ignorar esses sofrimentos. Sigmund Freud em "O mal-estar na civilização" (1930) identifica a experiência do sofrimento psíquico a partir da subjetividade dos sujeitos, e não apenas como uma questão médica - referente à fisiologia humana - ou moral - no que se refere á correção e educação -, como era vista anteriormente aos seus estudos.

A vida, tal como nos coube, é muito difícil para nós, traz demasiadas dores, decepções, tarefas insolúveis. Para suportá-la, não podemos dispensar paliativos (...). Existem três desses recursos, talvez: poderosas diversões, que nos permitem fazer pouco de nossa miséria, gratificações substitutivas, que a diminuem, e substâncias inebriantes, que nos tornam insensíveis a ela (FREUD, 1930, p. 20).

Se por um lado nos apoiamos na ideia do autor que afirma que o sofrimento foi se modificando ao longo do tempo através do sentido da experiência da dor psíquica e que também afirma que existem três pilares básicos para o homem suportar o sofrimento, é importante perceber como determinados estados de ser que derivam de um sofrimento independem do modo e do tempo nos quais são descritos, bem como compreender como essas transformações foram acontecendo dentro e a partir desses três recursos trabalhados por Freud.

Para o autor, o conceito de Unbehagen in der kultur - traduzido do alemão para o português como mal-estar na sociedade, utilizando a ideia de desabrigo, de um ambiente hostil -, é o paradigma da psicanálise que descreve o indivíduo desabrigado que vive em um mal-estar em civilização. Christian Dunker em "Mal-estar, sofrimento e sintoma: Uma psicopatologia do Brasil entre muros" (2015) traz uma tradução livre do conceito desenvolvido por Freud.

O problema para traduzir Unberhagen é, portanto, encontra uma palavra que responda tanto à série do desprazer-insatisfação quanto à série do infortúnioinfelicidade, de tal forma que contenha a experiência de mundo como espaço, lugar ou posição. O mal-estar não é apenas uma sensação desagradável ou um destino circunstancial, mas o sentimento existencial de perda de lugar, a experiência real de estar fora de lugar (DUNKER, 2015, p. 41).

Essa noção de mal-estar abarca o que consideramos como angústia, embora não se limite apenas a isso. A angústia para Freud se apresenta como "ausência ou perda de um objeto", um “estado afetivo, ou seja, uma união de determinadas sensações da série prazer-desprazer” (p.161), na qual foi incorporado subjetivamente ao indivíduo. Assim, compreendemos que a ideia do angustiar-se se constitui de variáveis, dentre elas, impulsos instituais, satisfação ou insatisfação sexual, obrigações sociais de felicidade, sucesso ou fracasso, entre outros. 
Para Freud, a angústia se manifesta entre três variações. A primeira é a angústia da consciência - que acontece em duas instâncias, consciente e inconscientemente -, considerada uma satisfação ou insatisfação para a qual se busca motivações.

De algum modo a angústia se acha por trás de todo sintoma, mas ora reivindica ruidosamente para si a consciência inteira, ora se oculta de modo tão perfeito, que nos vemos obrigados a falar de angústia inconsciente ou — se quisermos ter uma mais limpa consciência [Gewissen] psicológica, já que a angústia é em princípio uma sensação — de possibilidade de angústia (FREUD, 1930, p. 69).

Essa angústia é responsável pela troca de "afetos reprimidos", pelos sentimentos reconhecidos ou não-reconhecidos, que permanecem inconsciente ou que "vêm a luz como um mal-estar”, como sentimentos de culpa, castigo, penitência. O segundo tipo de angústia é a realista, compreendida como uma reação a um possível perigo externo que é capaz de causar uma experiência traumática.

Analisando a angústia realista, nós a reduzimos a um estado de elevada atenção sensorial e tensão motora, que chamamos de disposição à angústia. Desta se desenvolveria a reação de angústia. Nela seriam possíveis dois desfechos. Ou o desenvolvimento da angústia, a repetição da antiga vivência traumática, limita-se a um sinal, e a reação restante pode adequar-se à nova situação de perigo, procedendo à fuga ou à defesa, ou a situação antiga prevalece, toda a reação se esgota no desenvolvimento da angústia e o estado afetivo torna-se paralisante e inadequado ao presente (FREUD, 1930, p. 161).

De todo modo, a angústia realista é o que viria a se tornar uma angústia moral, ante o mundo externo, capaz de contemplar um momento traumático que não pode ser liquidado facilmente. Por fim, o terceiro tipo de angústia, a neurótica, é observada por Freud em três condições específicas: (1) enquanto angústia geral livremente flutuante, na qual o indivíduo se encontra disposto a ligar-se as novas possibilidades que lhes surgirem; (2) uma relação com a ideia de fobia, na qual o indivíduo reconhece um possível perigo diante de si mas que é desproporcional a angústia que se instala nele; (3) e em forma de bisteria, caracterizada pelas neuroses diversas que surgem sem algum motivo aparente e se mantém em um estado mais duradouro.

Freud relaciona os três tipos de angústia acima desenvolvidos sob a ótica das dependências do eu: a angústia realista considerada a partir do mundo externo e de suas influências; a angústia de consciência a partir do Super-eu - como uma pulsão de morte destrutiva no âmbito psíquico; e a angústia neurótica através do ID - aspecto inconsciente da personalidade do indivíduo que inclui comportamentos instintivos. Desse modo, podemos compreender como as estruturas do aparelho psíquico humano são atingidas por grandes influências, sejam elas de modo interno ou externo. 
Freud identifica também como o ser humano deposita no mundo externo uma responsabilidade sobre sua própria felicidade, se tornando refém de aprovações alheias a si mesmos que possam saciar suas carências. Assim, para o autor, agir sobre os impulsos dos instintos faz com que os indivíduos poupem uma parcela do sofrer.

Esse tipo de defesa contra o sofrimento já não lida com o aparelho sensorial; busca dominar as fontes internas das necessidades. De modo extremo isso ocorre ao se liquidar os instintos, como prega a sabedoria do Oriente e como praticam os iogues. (...) Com isso o propósito da satisfação não é absolutamente abandonado; uma certa proteção contra o sofrer é alcançada, pois a não satisfação dos instintos subjugados não é sentida tão dolorosamente como a dos não inibidos. Em troca, há uma inegável diminuição das potencialidades de fruição. A sensação de felicidade ao satisfazer um impulso instintual selvagem, não domado pelo Eu, é incomparavelmente mais forte do que a obtida ao saciar um instinto domesticado. O caráter irresistível dos impulsos perversos, talvez o fascínio mesmo do que é proibido, tem aqui uma explicação econômica" (FREUD, 1930, p. 24).

Podemos perceber nessa reflexão de Freud que o indivíduo busca inconscientemente novas formas de não depender do mundo exterior, e busca novas formas de se satisfazer através de processos internos cada vez mais característicos, de acordo com seus desejos - e isso inclui fantasias, distanciamento do mundo real, que muitas vezes leva o indivíduo a projetar no outro suas ilusões.

O âmbito de que se originam tais ilusões é aquele da vida da fantasia; quando ocorreu o desenvolvimento do sentido da realidade, ele foi expressamente poupado do teste da realidade e ficou destinado à satisfação de desejos dificilmente concretizáveis. Entre essas satisfações pela fantasia se destaca a fruição de obras de arte, que por intermédio do artista se torna acessível também aos que não são eles mesmos criadores. Quem é receptivo à influência da arte nunca a estima demasiadamente como fonte de prazer e consolo para a vida. Mas a suave narcose em que nos induz a arte não consegue produzir mais que um passageiro alheamento às durezas da vida, não sendo forte o bastante para fazer esquecer a miséria real (FREUD, 1930, p. 25).

Freud descreve uma sociedade que fantasia satisfações, que cria em um mundo imaginário condições específicas e confortáveis para se viver, que evita conflitos e desprazeres em busca de uma autossuficiência. $\mathrm{O}$ angustiar-se, de tão comum e dolorosa aos indivíduos, se torna uma vivência na qual as pessoas querem se poupar. Contudo, a posição de conforto em meios aos conflitos também é capaz de causar angústia: imagine alguém que vive em uma cidade bastante movimentada e em determinado momento, essa pessoa busca uma total tranquilidade. Essa tranquilidade extrema pode ter um papel inverso, o de angustiar mais ainda o indivíduo, pois este, não está habituado a um ambiente totalmente silencioso. Assim, posições de conforto também carregam em si, um desconforto.

Não há, aqui, um conselho válido para todos; cada um tem que descobrir a sua maneira particular de ser feliz. Fatores os mais variados atuarão para influir em 
sua escolha. Depende de quanta satisfação real ele pode esperar do mundo exterior e de até que ponto é levado a fazer-se independente dele; e também, afinal, de quanta força ele se atribui para modificá-lo conforme seus desejos. Já neste ponto a constituição psíquica do indivíduo, à parte as circunstâncias externas, será decisiva. Aquele predominantemente erótico dará prioridade às relações afetivas com outras pessoas; o narcisista, inclinado à autossuficiência, buscará as satisfações principais em seus eventos psíquicos internos; o homem de ação não largará o mundo externo, no qual pode testar sua força. (...) Toda decisão extrema terá como castigo o fato de expor o indivíduo aos perigos inerentes a uma técnica de vida adotada exclusivamente e que se revele inadequada (FREUD, 1930, p. 27-28).

Desse modo, percebemos uma busca incessante pela felicidade, seja pela busca em si ou pela ausência de angústia, de infelicidade. Aprendemos que é preciso se reinventar constantemente nos processos produtivos diários - como no trabalho, no lazer, na saúde e nos espaços que regem o cotidiano. Para Freud (1930), são esses parâmetros de felicidade que determinam quando uma vida segue um ritmo considerado aceitável para ser vivida pela produtividade, pelo dinamismo e pela ocupação. São esses parâmetros que delimitam uma vida social que é, ao mesmo tempo, os dois extremos: de um lado, uma busca infinita por uma felicidade, e do outro lado, nosso desamparo e angústia.

Para Freud, cada indivíduo é capaz de buscar e encontrar sua forma ou formas legítimas de felicidade, seja em si - uma autossuficiência -, no outro - como uma projeção -, ou no mundo externo. "Em nenhum desses caminhos podemos alcançar tudo o que desejamos" (p.28), o que nos faz compreender que não é preciso escolher uma dentre elas, mas vivenciar experiências e quebrar barreiras que possibilitem uma felicidade legítima.

Acreditamos que o êxito não obrigatoriamente se revele como felicidade legítima. Cabe aqui ao indivíduo se utilizar de seus métodos também para avaliar e adaptar seus feitos de modo a lhe proporcionar prazer. Em suma, existem variados caminhos possíveis para a felicidade, mas nenhum deles é tão seguro a ponto de se depositar total credibilidade. O domínio legítimo da satisfação ou da insatisfação, da felicidade ou da infelicidade, da angústia ou do conforto em existir, são categorias que vão além de uma análise clínica, pois não se encontram em um espaço de tempo cronológico definido, visto que se modificam ao longo do anos e se transformam as formas de sofrimento e de lidar com esses sofrimentos e suas angústias.

Contudo, não é porque carregam em si uma historicidade, que o tempo cronológico irá definir os sintomas, angústias e sofrimentos, mas, que como atos sociais que se modificam e se resignificam, essas formas de experiência carregam em si um potencial reflexo da sociedade.

Desse modo, é importante perceber o ser humano como sujeitos em constante transformação, apontamento feito com grande êxito pelo filósofo alemão Martin Heidegger no início do século XX. 


\section{SER-PARA-A-MORTE EM HEIDEGGER}

Tendo o ser humano como um ser imperfeito, aberto, inacabado; lançado ao mundo sem seu consentimento ou querer, sua existência é determinada pelas circunstâncias da vida, sejam elas históricas ou sociais. Marcado pela adversidade, o ser humano carrega consigo uma certa quantidade de sofrimento premeditada, cujos sofrimentos derivam da dor, da injustiça, do medo, das inseguranças, dos fracassos, dos lutos, das catástrofes, do envelhecimento, de doenças, da morte. Dito isto, a existência humana não é plenamente feliz, visto que cada indivíduo se depara e lida de maneira diferente com os conflitos existentes.

Nesse sentido, Martin Heidegger em Ser e Tempo (1927\2015) afirma que a vida humana é marcada pela angústia - tida como característica fundamental da existência humana a partir do momento em que o homem em sua natureza, desperta para sua própria consciência e questiona sua própria existência. Para o autor, é na angústia que o ser humano sente o nada, a efemeridade e a igualdade exacerbada das coisas, onde tudo caminha para o seu fim e decadência. É na angústia, ainda segundo Heidegger, que o homem percebe que é um ser-para-a-morte e não para a vida, pois é na morte que se retira todo o sentido da vida e se torna possível - como possibilidade - uma abertura do ser.

Interpretar o movimento de passagem da presença para o ser simplesmente dado
perde a base fenomenal na medida em que o ente remanescente não é uma mera
coisa corpórea. Do ponto de vista teórico, mesmo o cadáver dado é ainda objeto
possível da anatomia patológica, cuja tendência de compreensão se orienta, não
obstante, pela ideia de vida. O ser ainda simplesmente dado é "mais" do que uma
coisa material, destituída de vida. Nele encontra-se algo não vivo, que perdeu a vida
(HEIDEGGER, 2015, p. 312).

O que Heidegger coloca não é a morte como ausência de presença do corpo, mas como possibilidade ontológica de seu ser, compreensão determinada por disposições, capaz de provocar em possibilidade a essência do indivíduo. A angústia carrega em si um poder de provocar uma morte em sentido ontológico, particular e subjetiva, derivada de todo um acúmulo de experiências, obrigações, imposições, normas, leis, regras etc, e é posta como essa percepção profunda da finitude da vida, como a possibilidade da revelação do ente, enquanto tal para o ser-aí, para o Dasein humano.

A indeterminação do amanhã e a incerteza do porvir também são apontadas como aberturas para a angústia ao Heidegger considerar como uma fuga da totalidade do indivíduo, pois é o ente que foge, que escapa - este caracterizado como coisa, simplesmente dado, limitável, objetivável e 
explicável. Em contrapartida, um indivíduo que em abertura, em compreensão determinada própria, se permite em possibilidade, ir ao encontro de sua essência, é compreendido como a presença do ser, onde o ser, ontológico, tem natureza própria, não se explica e nem se determina, ele se expande.

Como único ser capaz de refletir sobre sua própria existência e de reconhecer profundamente a vida como finita, o ser humano tem como nessa mesma questão, a origem de sua angústia, ao considerar as inúmeras possibilidades e variações da vida. A ausência de uma natureza determinada e pronta coloca o homem em uma abertura imensa em relação ao que está posto social e historicamente, assim, é que a angústia se manifesta de maneira indeterminada.

É na disposição da angústia que o estar-lançado na morte se desvela para a
presença de modo mais originário e penetrante. A angústia com a morte é
angústia "com" o poder-ser mais próprio, irremissível e insuperável. O próprio
ser-no-mundo é aquilo com que ela se angustia. O porquê dessa angústia é o puro
e simples poder-ser da presença. Não se deve confundir a angústia com a morte
e o medo de deixar de viver. Enquanto disposição fundamental da presença, a
angústia não é um humor "fraco", arbitrário e casual de um indivíduo singular e
sim a abertura de que, como ser-lançado, a presença existe para seu fim. Assim,
esclarece-se o conceito existencial da morte como ser-lançado para o poder-ser
mais próprio, irremissível e insuperável. Com isso, ganha nitidez a delimitação
frente a um mero desaparecer, a um mero finar ou ainda a uma "vivência" do
deixar de viver (HEIDEGGER, 2015, p. 327).

Assim, podemos compreender a angústia como uma abertura do ser em sua capacidade de mudança diante essa disposição, como ser-lançado para um fim, fim este da vida não em sentido biológico, mas ontológico, carregado de subjetivações e capaz de transformar a presença de um ser angustiado em sua essência mais pura e originária. "A morte é a possibilidade mais própria da presença” (p. 340), capaz de se lançar a cura, ou seja, no seu estado mais puro de autoconhecimento.

Sócrates (469 - 399 a.C.) ao afirmar que "a vida irrefletida não vale a pena ser vivida", identifica que uma vida que não é questionada, é uma vida de ignorância, sem moralidade, e estimula um pensamento sobre o autoconhecimento, o próprio ser em sua essência. Para que essa essência seja alcançada de modo satisfatório, é preciso não somente estar lançado no mundo, mas se questionar, assumir a angústia e se colocar diante dessa angústia.

Pois existir faticamente não é somente um poder-ser-lançado no mundo, genérico e indiferente, já sendo também um empenhar-se no "mundo" das ocupações. Nesse decadente ser-junto-a, anuncia-se a fuga da estranheza, isto significa, do ser-para-a-morte mais próprio. Existência, facticidade, decadência caracterizam o ser-para-o-fim, constituindo, pois, o conceito existencial da morte. No tocante à sua possibilidade ontológica, o morrer funda-se na cura (HEIDEGGER, 2015, p. 327).

Assim, a presença só pode ser ela mesma quando se direciona à angústia de modo a refletir sobre sua existência; se deparar com a morte, enquanto possibilidade ontológica, e buscar por uma 
vida autêntica através de um estado mínimo de abertura do ser. Heidegger considera o estado de morte em um sentido privilegiado, considerando esse processo possível a todos os indivíduos, porém, realizado por poucos, visto que o impessoal se empenha em reverter e cessar a angústia de modo brusco e sem reflexão (p. 325).

Enquanto possibilidade, a presença é, em essência, uma antecipação (p. 422). O antecipar-se, terminologicamente, é caracterizado por um porvir, que aponta a presença de modo a vir-a-si como seu poder-ser mais originário, assim, uma abertura do ser se revela em sentido próprio enquanto antecipação, enquanto possibilidade mais extrema. Ou seja, como um projetar-se para seu poderser mais próprio, a antecipação surge enquanto possibilidade de existir de modo autêntico. $\mathrm{O}$ anteceder-a-si-mesmo é parte essencial da transformação do ser enquanto cura. A cura enquanto decisão antecipadora que permite que o ente se lance para a morte já é um passo enquanto possibilidade de abertura do ser.

Em seu ser, a presença já sempre se conjugou com uma possibilidade de si mesma (...) já sempre antecedeu a si mesma. A presença já está sempre 'além de si mesma', não como atitude frente aos outros entes que ela mesma não é, mas como ser para o poder ser que ela mesma é (HEIDEGGER, 2015, p. 258).

Assim, a compreensão da presença conduz o ser do homem a suas possibilidades, enquanto ser autêntico, capaz de refletir sobre a dimensão do possível, de um ainda-não que pode vir a ser. $\mathrm{O}$ que o ser em sua essência ainda não é de fato, em realidade, já pode se configurar como possibilidade, enquanto poder-ser, para em seguida se tornar real. Heidegger caracteriza esse processo como compreensão, capaz de constituir o ser da pre-sença na medida em que esta pode formar essas variadas possibilidades.

Enquanto descoberta compreensiva do incompreensível, todo explicar tem suas raízes no compreender primordial da presença. Apreendido de modo existencialmente originário, compreender significa: ser, projetando-se num poder-ser, em virtude do qual a presença sempre existe. O compreender abre o poder-ser próprio de tal maneira que, compreendendo, a presença, de algum modo, sempre sabe a quantas ela mesma anda. Esse "saber" não significa, contudo, ter descoberto um fato, mas manter-se numa possibilidade existenciária. $O$ não saber que lhe corresponde não consiste numa ausência do compreender, mas deve ser considerado um modo deficiente de se projetar o poder-ser" (HEIDEGGER, 2015, p. 421).

“Na presença, enquanto ela é, sempre se acha algo pendente, que ela pode ser e será" (p.12). Dito isto, o compreender se configura aqui não como um tipo de conhecimento determinado, mas como um projetar-se na possibilidade. Para Heidegger, na maior parte das vezes, essa abertura não acontece com facilidade, e isso se dá pelas mutações do porvir do ente. Isso reforça a necessidade 
de uma disposição primária ou prévia para a compreensão do ser, e então, se lançar na possibilidade, na presença como um poder ser.

A efemeridade do cotidiano, o escape decadente, é um ser-para-a-morte impróprio (p. 336). Em sua capacidade de desviar-se, o ente não se lança às variadas possibilidades e não propõe-se uma abertura do pre, impossibilitando um poder-ser próprio. Essa não-disposição provoca a angústia, que, por sua vez, não obrigatoriamente implica uma retomada ou uma abertura do ser, mas sim, uma estranheza inerente ao ser. Assim, a angústia se manifesta como possibilidade de um poder-ser próprio potencialmente existenciária da presença.

A insignificância do mundo, aberta na angústia, desvela a nulidade das ocupações,
a impossibilidade de projetar-se um poder-ser da existência primariamente
fundado na ocupação. Desvelar essa impossibilidade significa, porém, deixar vir
à luz a possibilidade de um poder-ser próprio. Que sentido temporal possui esse
desvelar? A angústia angustia-se pela presença nua e crua, enquanto lançada na
estranheza. Ela recoloca o puro que (se é) do estar-lançado mais próprio e
singular. Esse recolocar não tem o caráter de um esquecer que se esquiva e nem
tampouco de uma recordação (HEIDEGGER, 2015, p. 430).

O esquecimento e o desamparo colocam a presença em todo lugar e em lugar nenhum. Deixam a presença perdida em meio a tantas possibilidades não apreendidas. Esse também é um fator da angústia cotidiana, bem como outros fenômenos diretamente relacionados a um angustiarse, a um vigor de ter sido, tais como a esperança - como um contraponto -, e a indiferença, capaz de se prender a tudo e a nada, de aceitar tudo e não contestar a nada, se mantém abandonado como que inerte ao mundo, a qual, sem dúvida, se caracteriza por uma presença imprópria.

Michel Foucault em A Hermenêutica do sujeito (2007\2010) desenvolve o pensamento de que em toda a história da humanidade sempre houve uma desconfiança e um certo receio com o porvir. Para Foucault, não se deixar preocupar com o porvir é um tema fundamental da prática de si e, além disso, o porviré o que de fato é preocupante. Ainda para o autor, o preocupar-se com o porvir e ver-se preso no que está diante, no que vem, está ligado com três aspectos fundamentais da prática de si.

O primeiro é caracterizado como o primado da memória. A preocupação com o porvir se manifesta comumente de modo negativo, porém, em relação à memória, essa preocupação aparece de forma positiva, carregada de nostalgia e capacidade de consciência história. Para Foucault (2010), existe uma reflexão cristalizada de que "não pode haver um pensamento sobre o porvir que seja ao mesmo tempo uma memória. E não pode haver uma memória que seja ao mesmo tempo um pensamento sobre o porvir" (p. 417), porém, o autor contesta ao afirmar que toda uma nova 
dimensão do que se caracteriza como consciência histórica será tardiamente alcançada quando se puder relacionar um olhar sobre a memória e um olhar para o porvir.

O segundo aspecto de uma preocupação com o porvir está relacionado a prática teórica, filosófica e ontológica.

O porvir é o nada: ele não existe, pelo menos para o homem; consequentemente, a seu respeito só se pode projetar uma imaginação que se assenta no nada. Ou então o porvir preexiste: se preexiste é porque é predeterminado; e, por isso, nenhum domínio podemos ter sobre ele. Ora, o que está em jogo na prática de si é precisamente poder dominar o que se é, em face do que é ou do que se passa. Ou nada ou predeterminado, o porvir nos condena ou a imaginação ou a impotência. Ora, estas são as duas coisas contra as quais é construída toda a arte de si mesmo, toda a arte do cuidado de si (FOUCAULT, 2010, p. 417).

Considerando o porvir como um lugar desconhecido e apenas projetável e imaginável, é válido considerar até que ponto o homem tem domínio sobre esse porvir, tanto em sua pequenez em relação ao porvir quanto por ser único agente transformador capaz de agir e refletir sobre o porvir. Por fim, o porvir escapa à percepção e se instala em um lugar de não pertencimento do homem, onde existe uma oposição entre os homens voltados para o porvir e homens que estão voltados para o passado e que fazem uso da lembrança. Essa oposição define uma dispersão e uma não reflexividade do pensamento sobre si mesmo, onde quem não se ocupa consigo mesmo, se ocupa com o porvir e se preocupar somente com o porvir, torna por gerar um homem que não se preocupa com o que consideramos tempo presente - pois se está disperso e ocupado demais com o porvir.

Dito isto, percebemos o porvir como uma preocupação real que, na maioria das vezes, anula uma vivência do presente, capaz de provocar angústia, medo, indiferença e alterar diretamente as percepções humanas sobre a realidade e sobre as formas de lidar com o cotidiano. Assim, o presente não é dado nem posto de modo linear entre passado e futuro, mas sim enquanto movimento de temporalização, que aconteceu, acontece e acontecerá de modo simultâneo, como a expressão heideggeriana do "do vigor de ter sido presente" enquanto campo de possibilidades.

\section{CONSIDERAÇÕES FINAIS}

Os acontecimentos da vida cotidiana dispersam o entendimento humano sobre si, e os desconecta de sua essência de modo a dispersar questões fundamentais da essência humana. Essa dispersão provoca o que Heidegger denomina como angústia, conceito desenvolvido ao longo do presente trabalho. A partir da possibilidade de abertura do ser, essa decisão de retomada de si, é que 
a presença pode se recuperar e se originar um ser transformador, em essência própria, autêntica e originária. Para Heidegger, a angústia não é um sintoma ou condição patológica, é um estado fundamental da existência humana, e é na angústia que surge a possibilidade do ser de sair da inautenticidade, na qual ele geralmente vive, para vir a assumir a autenticidade da sua existência.

A partir desse pensamento, questionamos a origem de um "sentido da vida" que, não nos é nado, nem imposto, mas que deve ser criado por cada sujeito em sua capacidade de refletir sobre si. Para Heidegger, esse "sentido da vida" deve ser buscado individualmente, pois, o homem é o único sujeito capaz de direcionar sua vida e existência a seu devir de suas realizações de maneira autêntica e originária. Ainda para o autor, alguns homens fogem da angústia e procuram preencher seu vazio de modo impessoal na banalidade do dia-a-dia, vivendo uma vida inautêntica, e aqui, a angústia faria o homem elevar-se da traição acometida para si mesmo, quando se deixa dominar pelas superficialidades do cotidiano.

Como principal resultado da presente pesquisa, podemos identificar duas perspectivas que, por mais distintas, se complementam de modo ontológico-existencial, onde, para Heidegger, em meio a angústia é que o homem se depara com a morte em sentido existencial, para em seguida, como possibilidade, retomar para si de modo autêntico e originário. Para Freud, sob a perspectiva da psicanálise, a angústia se caracteriza como um acontecimento resultante de confrontos com a morte, com potencialidades patológicas.

Freud também percebe que, embora haja diferentes maneiras de lidar com o mal-estar, a angústia se configura como uma questão possível a todos os indivíduos, considerando uma variedade de contextos e sintomas, enquanto para Heidegger, essa angústia surge de modo consciente a partir de uma mínima compreensão de si, para em seguida, em possibilidade, haver uma abertura do ser, capaz de modificar uma vida inautêntica em uma vida refletida.

\section{REFERÊNCIAS BIBLIOGRÁFICAS}

DUNKER, Christian. Mal-estar, sofrimento e sintoma: Uma psicopatologia do Brasil entre muros. São Paulo: Boitempo, 2015.

FOUCAULT, Michel. A Hermenêutica do sujeito: curso dado do College de France (1981-

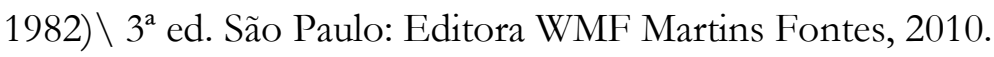

FREUD, Sigmund (1927). Inibição, sintoma e angústia. In: Obras psicológicas completas de Sigmund Freud: edição standard brasileira. Rio de Janeiro: Imago, 1996. 
(1930). O mal-estar na civilização. In: Obras psicológicas completas de Sigmund Freud: edição standard brasileira. Rio de Janeiro: Imago, 1996.

HEIDEGGER, Martin. Ser e Tempo. $10^{a}$ ed. Petrópolis, RJ: Vozes; Bragança Paulista, SP:
Editora
Universitária
São
Francisco,
2015. 